\title{
Uma contribuição do design à agricultura por meio da avaliação ergonômica das embalagens plásticas de 20 litros para agrotóxicos
}

\author{
A contribution of the design to agriculture trough an ergonomic \\ evaluation of the 20 liters plastic packings bottles for agrochemicals
}

\author{
Cristiane Affonso de Almeida Zerbetto ${ }^{1 *}$; Anderson Ogasawara Gimenez \\ Nayara Annoue Kague ${ }^{3}$
}

\begin{abstract}
Resumo
Um dos problemas enfrentados no cotidiano do trabalhador rural é a dificuldade no manuseio das embalagens de 20 litros para agrotóxicos, isto porque normalmente são grandes, pesadas, possuem pegas inadequadas formalmente e dimensionalmente e o sistema de abertura da tampa e do lacre de vedação são ineficientes. Pensando em uma forma de torná-las mais práticas e funcionais foram analisadas as embalagens fabricadas pela empresa Cimplast Ltda. e utilizadas pela indústria Milênia Agro Ciência S.A., para que posteriormente, com base em dados práticos da pesquisa de campo e em estudos teóricos sobre o design de embalagens, ergonomia, usabilidade e agrotóxicos, fosse produzido um guia de parâmetros ergonômicos destinado às indústrias que fabricam esse tipo de embalagem. Este guia, como produto final desta pesquisa, trará informações importantes e bem fundamentadas cientificamente, com linguagem simples e prática, visando facilitar as indústrias no processo de consulta durante a elaboração das embalagens, pois apesar dos dados nele contidos estarem disponíveis na literatura, as empresas dispõem de pouco tempo hábil para pesquisá-los no momento do desenvolvimento de seus produtos.

Palavras-chave: Ergonomia, embalagem, agrotóxico, usabilidade
\end{abstract}

\begin{abstract}
One of the problems faced in the daily life of the agricultural worker is the difficulty in the handle of the big packing bottles of agrochemicals, because they are normally very big, heavy and the handles are inefficient. Thinking about one way of making them more practical and useful the bottles manufactured by the company Cimplast Ltda and used by the industry Milênia Agro Ciência S.A. had been analyzed so that later, based in already carried trough studies in design, packing, ergonomics, anatomy and usability, a guide can be produce destined to the industries that produce this type of packing, so, by means of theoretical support, these companies can produce packing bottles that could adapt better to the user or could reformulate the existing models. For the production of the content of the guide some bibliographical references and technical norms directed to these packing bottles had been overcome. Later a research of field with the potential users was carried out, which it could confirm or refute the referring hypotheses to the usability raised initially. After the evaluation of the ergonomic problems presents in these packing bottles, tables of contents for better illustrate the research had been produced and, later, the data had been questioned based in the theoretical referential. The guide, which is the final product of this work, will bring important and scientifically based information, with simple and practical language, aiming to facilitate for the industries the process of production of the packing bottles, therefore although the data contained in it is available in literatures the companies make use of little time for research
\end{abstract}

Key words: Ergonomics, packing, agrichemicals, usability

1 Universidade Estadual de Londrina. E-mail: cra@uel.br

2 Universidade Estadual de Londrina

3 Universidade Estadual de Londrina; Fundação Araucária.

* Autor para correspondência 


\section{Introdução}

As condições favoráveis de trabalho no campo são de suma importância, pois aumentam a produtividade e, conseqüentemente, a produção agrícola é potencializada, gerando maiores lucros aos agricultores e diminuindo consideravelmente os riscos de danos aos quais eles estão expostos. $\mathrm{O}$ ambiente de trabalho e os equipamentos necessários para realizar as tarefas precisam estar adaptados ao homem e não o contrário. Portanto, os estudos de design e ergonomia têm como objetivo desenvolver novos produtos ou aprimorar os já existentes, tornando-os mais práticos e fáceis de usar pelo consumidor.

De acordo com Pheasant (1988), a Ergonomia tem por objetivo adaptar o trabalho ao trabalhador e o produto ao usuário. Percebe-se que de forma geral esta ciência tem o homem como foco principal, e os demais elementos devendo funcionar em relação ao mesmo, jamais o inverso.

Entre os objetos de estudo da ergonomia está a ação do manejo, a qual é definida por Gomes (1995, p. 2) como o ato de pegar, movimentar, pôr, manter ou cessar o funcionamento de um produto por meio de atos de simples pega, empunhadura ou acionamento de elementos. A pega se dá pelo envolvimento dos extremos dos dedos ao redor dos componentes e a empunhadura se dá pelo movimento palmar ao redor dos equipamentos (BULLINGER; SOLT apud PASCHOARELLI; COURY, 2000). Existem dois tipos de manejo: o fino (executado pela ponta dos dedos) e o manejo grosseiro cujo movimento exige muita força e é executado pelo punho e pelo braço. Além disso, há também dois tipos de desenho para o manejo: o geométrico que proporciona uma menor superfície de contato com as mãos e o antropomorfo que permite maior firmeza de pega e maiores forças (IIDA, 2005).

Com a ajuda da biomecânica, que segundo Iida (1998), trata da relação do homem em seu trabalho, estudando as conseqüências dos movimentos músculos-esqueléticos, das posturas assumidas e das forças despendidas na execução de uma tarefa; torna-se possível analisar os movimentos realizados para a abertura das embalagens e estudar o esforço realizado pelos usuários.

As posturas e os movimentos inadequados na realização de tarefas provocam lesões nos músculos, ligamentos e articulações, ocasionando dores e traumas (DUL; WEERDMEESTER, 1995). Neste sentido, o desempenho positivo ou negativo do usuário durante a execução da tarefa está diretamente relacionado à maneira que o produto se apresenta (forma, peso, textura) e como este é manuseado.

Outro componente fundamental a ser estudado é a adequação dimensional dos equipamentos que o homem utiliza em seu trabalho. Considerando a definição de Iida (1998, p. 101) "a antropometria trata de medidas físicas do corpo humano", buscando definir dimensões que sejam estatisticamente representativas das comunidades humanas.

As principais questões antropométricas relacionadas aos produtos que sofrem empunhadura são: forma, tamanho e as capacidades dimensionais dos dedos, palma da mão e pulso. Todos os fatores citados acima refletem no maior conforto e menor risco para os usuários, garantindo assim uma melhor usabilidade, para Rio e Pires (2001), os designers devem sempre observar os fatores de usabilidade ao se projetar um produto: incapacidade (físicas), posicionamento das articulações, risco de acidentes, texturas, cantos vivos (evitar), destros e canhotos, diferenças sexuais, dimensões (antropometria), idade e estereótipo popular (levar em conta os hábitos da maioria da população ao executar uma ação).

Diante destes embasamentos teóricos e considerando a relevância da agricultura dentro do contexto sócio/econômico do nosso país, torna-se fundamental a contribuição do design, com base nos fundamentos ergonômicos às ciências agrárias; e entre os produtos que fazem parte destas ciências estão as embalagens plásticas de 20 litros para agrotóxicos. 
Estas informações, quando bem aplicadas no desenvolvimento dos projetos das embalagens, podem contribuir significativamente para o melhor desempenho das atividades com menor gasto energético, tornando a vida dos agricultores, muitas vezes desvalorizados e desmotivados, um pouco mais salutar e agradável, com um produto que realmente foi pensado com base em parâmetros humanos importantes para eles.

Percebe-se no decorrer da história do design que pouco tem se aplicado os conceitos ergonômicos aos produtos de pequeno porte vinculados à agricultura, dentre estes encontram-se as embalagens plásticas de agrotóxicos disponíveis no mercado.

Chama-se atenção para o crescimento do uso dos materiais plásticos ou polímeros, 200 milhões de toneladas /ano, resultando em novas tecnologias para esses materiais devido ao uso significativo (MANO; MENDES, 2000). Entre os polímeros que se destacam neste segmento está o Polietileno, sendo o Polietileno de Alta Densidade a segunda resina mais reciclada no mundo (INSTITUTONACIONAL DE PROCESSAMENTO DE EMBALAGENS VAZIAS - INPEV, 2005b).

Um dado relevante para este estudo foi apontado pelo presidente do Instituto Nacional de Processamento de Embalagens Vazias, João César Rando, onde ele relata que no ano de 2005 foram comercializadas 38 mil toneladas de embalagens de agrotóxicos, o qual realmente justifica a realização de pesquisas que possam contribuir para o aprimoramento do desempenho destes produtos (INPEV, 2005a).

Entre as embalagens vazias de agrotóxicos devolvidas, o Paraná é o que aparece na frente, com um volume de 2.358 toneladas, sendo este um estado de destaque, tanto no consumo destas embalagens, como na conscientização da devolução das mesmas (DESENVOLVIMENTO..., 2005). Existem vários tipos de embalagens plásticas para agrotóxicos, porém as mais problemáticas são as de 20 litros.
Este apontamento é feito com base no peso destas embalagens quando já envasadas, aproximadamente $23 \mathrm{~kg}$, sendo necessário no momento de verter o produto a utilização das duas mãos, porém algumas delas apresentam apenas uma pega superior dificultando muito a ação, podendo ocorrer o derramamento de um produto caro e altamente perigoso para a salubridade do usuário, ou mesmo o comprometimento dos discos intervertebrais. Sabe-se que $60 \%$ das lesões musculares têm sido ocasionadas pelo levantamento de cargas de forma indevida (BRIDGER apud IIDA, 2005).

Além do fator peso/quantidade de pegas, devese destacar a grande dificuldade encontrada para romper o lacre no bocal da embalagem podendo o usuário machucar-se durante esta tarefa, por entrar em contato direto com o agrotóxico, pois muitas vezes usa o dedo para efetuar a ação.

Fundamentado nestas observações a pesquisa propõe dois objetivos de forma geral. Primeiramente, verificar os problemas de usabilidade encontrados durante o manuseio das embalagens plásticas de 20 litros para agrotóxicos - a Coex, a Mauser e a Retangular-fabricadas pela empresa Cimplast Ltda. e utilizadas pela indústria Milênia Agro Ciência S.A., e com base nos dados teóricos levantados e nos problemas de usabilidade encontrados na pesquisa de campo, elaborar um Guia de Parâmetros Ergonômicos para o Design ou Redesign das Embalagens Plástica para Agrotóxicos, direcionado às indústrias destas.

Dentre os objetivos específicos pretende-se verificar e analisar os modelos das embalagens plásticas de 20 litros para agrotóxicos junto à empresa Cimplast Ltda.; averiguar se os modelos de embalagens selecionadas apresentam a quantidade e o design da pega adequados para o seu manuseio; apontar os problemas de usabilidade apresentados durante o manuseio destas embalagens; contribuir de forma prática e efetiva com o desenvolvimento de embalagens para agrotóxicos ergonomicamente corretas. 


\section{Materiais e Métodos}

Participaram do experimento 50 trabalhadores rurais do gênero masculino, com idades entre 18 e 64 anos, apresentando funções motoras normais. Estes participantes foram divididos em 05 subgrupos, tendo como variável a idade. Com relação à idade, utilizou-se como base a divisão das tabelas de antropometria dos autores Panero e Zelnik (1987), a qual é amplamente aplicada por ergonomistas; esta consiste no seguinte: participantes de 18 a 24 anos,
25 a 34 anos, 35 a 44 anos, 45 a 54 anos e 55 a 64 anos. Quanto ao gênero, a porcentagem será 100\% de homens, pois estes representam a maioria dos usuários dos produtos.

Das embalagens de 20 litros (Cimplast Ltda.) utilizadas pela empresa Milênia Agro Ciência S.A, foram selecionados 3 modelos, Coex, Mauser e Retangular (Figura 1), com sistemas de usabilidade diferentes, possibilitando assim uma análise mais completa dos requisitos de uso.

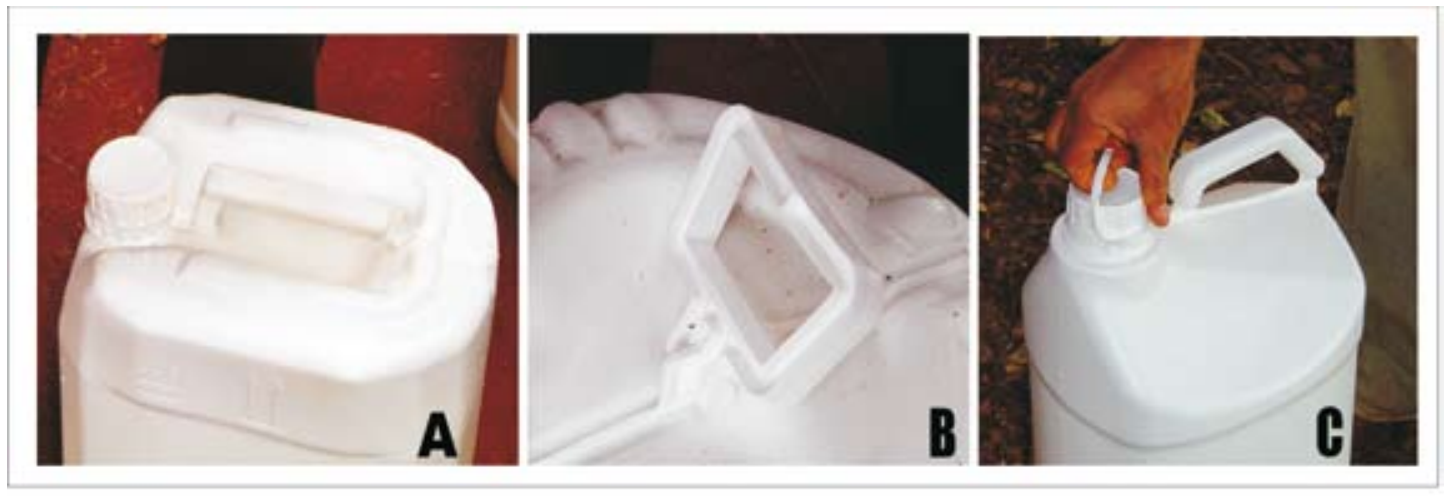

Figura 1. Embalagens usadas no estudo. A. Mauser, B. Coex e C. Retangular.

Os testes foram realizados em propriedades rurais próximas da cidade de Sabáudia (PR) e na COROL - Cooperativa Agroindustrial - Sabáudia, simulando situações reais de uso. A forma como estes ocorreram encontram-se a seguir: no local do teste os participantes recebiam uma explicação de toda a metodologia do ensaio; este submetia-se ao teste de manuseio das embalagens, para verificação da eficiência e dos problemas de usabilidade das pegas; logo em seguida o mesmo abria a embalagem, derramava o conteúdo desta para o interior de um pulverizador, depois a fechava; todas estas ações foram executadas com a mão de sua preferência (direita e/ou esquerda); e ao final do experimento, o participante respondia os questionários referentes a cada embalagem testada.

Primeiramente foi realizado um pré-teste com 5 pessoas com o objetivo de avaliar os instrumentos de pesquisa e corrigir as possíveis falhas. $\mathrm{O}$ ensaio foi realizado a partir do método de Observação Sistemática (MORAES; MONT'ALVÃO, 2000). Outro método utilizado foi o da Inquirição da Tarefa, que se baseia na busca metodológica de informações e quantificações de resultados, podendo esse utilizarse de vários instrumentos. Nesta pesquisa, por exemplo, foram utilizados 3 questionários, sendo um para cada tipo de embalagem, com perguntas fechadas, contendo alternativas dicotômicas e hierarquizadas, e uma única pergunta aberta no terceiro questionário, para que os participantes pudessem responder esta pergunta após já ter experimentado as três embalagens. Foram realizados questionamento quanto ao desconforto e posição da pega, peso da embalagem, se esta já causou ferimentos e problemas quanto a verter o produto. 


\section{Resultados e Discussão}

É necessário salientar que todas as embalagens em questão possuem manejo geométrico, ou seja, aquele que se assemelha às figuras geométricas regulares, os quais proporcionam menor superfície de contato com as mãos e permitem maior variação de pega, porém ocasionam alguns pontos de tensão na mão e transmitem menos força (IIDA, 1998).

Percebe-se que o maior desconforto em relação à pega está na embalagem Mauser, pois esta possui a alça localizada numa cavidade no corpo da embalagem, o que dificulta o movimento da mão e dos dedos dos usuários. De acordo com Stier e Meyer (apud GRANDJEAN, 1998) a altura da articulação entre a primeira e a segunda falange do dedo médio é de $22 \mathrm{~mm}$, considerando que a altura do vão livre entre o corpo da embalagem e a pega é de apenas
$30 \mathrm{~mm}$. Conclui-se que quando manuseada, os dedos estarão flexionados e, portanto, não estarão acomodados confortavelmente (Figura 1A).

Com $32 \%$ de reprovação está a embalagem Coex (Tabela 1), que apresenta uma leve curvatura na alça causando a antecipação da fadiga nos dedos médio e anular, pois estes estão localizados justamente nesta saliência, além da presença de canto vivo na pega, o que acaba ampliando o desconforto aos usuários. Segundo Kinoshita et al. (1996) conforme o peso do objeto aumenta a força exercida pelos dedos médio, anular e polegar, aumenta proporcionalmente (Figura 1B). A largura da alça desta embalagem é problemática, já que mede $85 \mathrm{~mm}$, tamanho insuficiente para comportar a largura média da mão (metacarpal) dos homens, que varia de $78 \mathrm{~mm}$ a 93 mm (IIDA, 1998).

Tabela 1. Síntese dos aspectos negativos em relação à cada embalagem.

\begin{tabular}{|c|c|c|c|c|}
\hline & & Coex & Mauser & Retangular \\
\hline \multirow[b]{2}{*}{ Desconforto ao pegar a embalagem } & SIM & $32 \%$ & $52 \%$ & $16 \%$ \\
\hline & NÃO & $68 \%$ & $48 \%$ & $84 \%$ \\
\hline \multirow{2}{*}{$\begin{array}{l}\text { O vão da pega da embalagem é estreito para a } \\
\text { mão }\end{array}$} & SIM & $36 \%$ & $12 \%$ & $4 \%$ \\
\hline & $\mathrm{NÃO}$ & $64 \%$ & $86 \%$ & $96 \%$ \\
\hline \multirow{2}{*}{$\begin{array}{l}\text { Inadequação da posição da pega da } \\
\text { embalagem }\end{array}$} & ADEQUADA & $82 \%$ & $48 \%$ & $80 \%$ \\
\hline & INADEQUADA & $18 \%$ & $52 \%$ & $18 \%$ \\
\hline \multirow{2}{*}{ Dificuldade para levantar e tombar a embalagen } & SIM & $30 \%$ & $76 \%$ & $90 \%$ \\
\hline & NÃO & $70 \%$ & $24 \%$ & $10 \%$ \\
\hline \multirow{2}{*}{ Necessidade de mais apoio (pega) para verter o produto } & SIM & $26 \%$ & $64 \%$ & $98 \%$ \\
\hline & NÃO & $74 \%$ & $36 \%$ & $2 \%$ \\
\hline
\end{tabular}

Por fim, a embalagem Retangular recebeu o menor índice de reprovação (Tabela 1), uma vez que apresenta medidas mais próximas às ideais estipuladas pela ciência ergonômica. Contreras (1996) recomenda pegas com diâmetro de $30 \mathrm{~mm}$ a $50,8 \mathrm{~mm}$ quando estas necessitam de forças para o manuseio. A alça em questão configura-se saliente ao corpo da embalagem, o que proporciona maior liberdade para a movimentação da mão e dos dedos, juntamente com as medidas do vão livre (38 mm de altura em sua parte mais alta e $105 \mathrm{~mm}$ de largura) e das dimensões da alça (20 $\mathrm{mm}$ de altura e $30 \mathrm{~mm}$ de largura) (Figura 1C). 
De acordo com os dados obtidos em relação ao vão da pega da embalagem, observa-se novamente que a embalagem Retangular recebeu maior índice de aprovação, o que reafirma sua eficácia em relação ao manuseio. Retomando os dados apresentados na Tabela 1, pode-se salientar que a pega desta é a mais satisfatória em comparação às outras embalagens, já que essa possui vão livre com altura de $38 \mathrm{~mm}$ e largura de $105 \mathrm{~mm}$, enquanto a Coex apresenta 37 $\mathrm{mm}$ de altura e $85 \mathrm{~mm}$ de largura e, a Mauser, 30 $\mathrm{mm}$ e $115 \mathrm{~mm}$ respectivamente. A justificativa para o resultado negativo da Coex e Mauser é distinta. Esta atende ao padrão de medida da largura, que supera os $100 \mathrm{~mm}$ recomendados por Grandjean (1998), porém sua altura é insuficiente já que, de acordo com Kinoshita, Murase e Bandou (1996) a espessura da mão (metacarpal) de 95\% dos homens é de $38 \mathrm{~mm}$. Já a Coex tem um vão de pega muito estreito em relação à medida da largura.

Referente à posição da pega da embalagem (Tabela 1) a manutenção da posição neutra das articulações durante a execução de uma tarefa deve ser mantida, pois assim os músculos são capazes de liberar a força máxima, além de permitir que os ligamentos das articulações permaneçam tencionados ao mínimo, favorecendo o manuseio do objeto.
O resultado exprime a preferência dos entrevistados pela posição da pega da Coex, isto porque sua alça é móvel e localiza-se no centro da superfície superior da embalagem, o que possibilita a movimentação do corpo da embalagem, ao invés da flexão palmar do pulso (Figura 1B).

As embalagens Mauser e Retangular possuem alça fixa (Figura 1A e C), característica que obriga o usuário a dobrar o pulso no momento de verter o produto, realizando o desvio ulnar, o que para Contreras (1996) pode prejudicar a força de pega, reduzindo-a em até $25 \%$ e causar tensões mecânicas nos músculos, ligamentos e articulações, ocasionando dores ou até mesmo traumas nas partes envolvidas (DUL; WEERDMEESTER, 1995).

Para que a embalagem seja levantada e tombada de forma eficaz é necessário que a mesma possua um conjunto de características de pega que auxilie o usuário a realizar estas tarefas. Portanto, para levantá-la utiliza-se à alça e para tombá-la fazse necessário o uso desta juntamente com a pega inferior (Figura 2). De acordo com Iida (2005), para iniciar o levantamento de um objeto é fundamental que a alça deste se localize a uma distância mínima de $400 \mathrm{~mm}$ do chão, caracterísca presente em todas as embalagens analisadas, o que confere a elas uma igualdade em relação a esse fator.
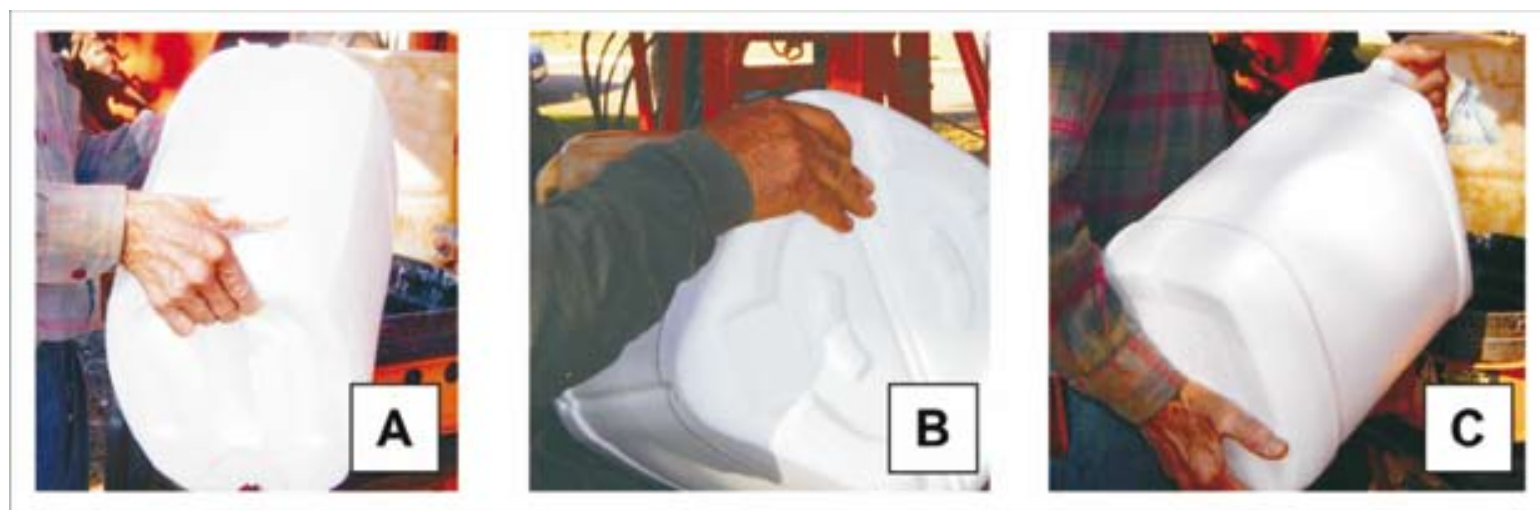

Figura 2. Pega inferior das embalagens A. Mauser, B. Coex e C. Retangular. 
De acordo com a dificuladade para levantar e tombar a embalagem a Coex (Figura 2C) recebeu a menor porcentagem sobre este item $(30 \%)$, resultado significativo, já que a Mauser e a Retangular tiveram índices altíssimos de reprovação, $76 \%$ e 90\% respectivamente (Tabela 1 ). Mesmo com um resultado satisfatório, a Coex apresenta alguns problemas em relação à pega. Sua alça flexionase apenas para frente e para trás, limitando os movimentos da mão, obrigando o usuário a segurar a embalagem sempre da mesma forma, para que o pulso mantenha-se na posição neutra (Figura 3).

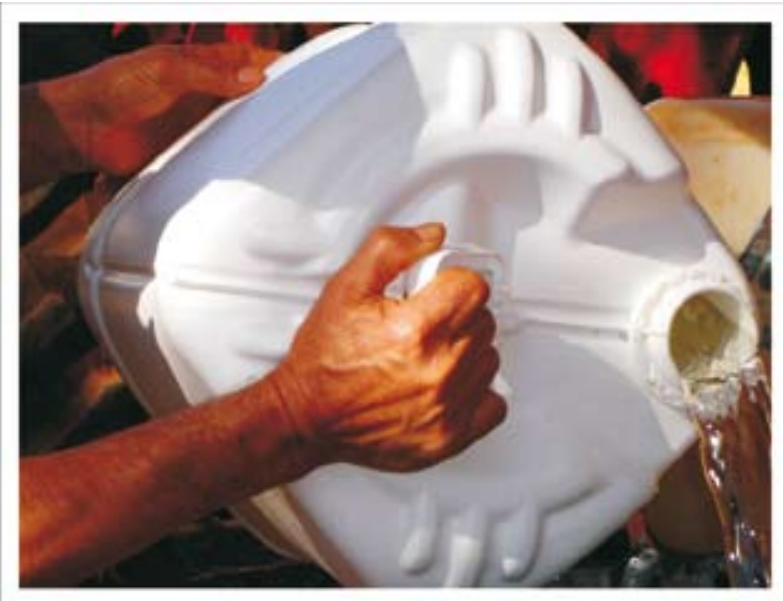

Figura 3. Posição neutra da pega na embalagem Coex.

Por sua vez, a embalagem Mauser apresentou uma porcentagem de $76 \%$ de insatisfação (Tabela 1), mesmo possuindo pega na parte inferior da embalagem (Figura 2B). Isso porque o problema está relacionado à alça que se configura inserida em uma reentrância no corpo do recipiente, não apresenta vão livre suficiente para comportar confortavelmente a mão dos usuários e, também, sua posição propicia a flexão do pulso, o que causa diminuição de até $50 \%$ da força de pega.

Como 90\% dos usuários disseram ter dificuldade para levantar e tombar a embalagem Retangular, comprova que a falta de apoio na base inferior desta prejudica efetivamente seu manuseio (Figura 2A).

Por fim, é necessário ratificar a importância que tem a morfologia das pegas nas embalagens, pois esta visa evitar a ocorrência de flexões e desvios do pulso que podem causar indisposições ocupacionais ao usuário de acordo com Laville (apud GOMES, 1995) (Figura 3).

Quanto a necessidade de mais apoio para verter o produto (Tabela 1) a embalagem retangular recebeu maior porcentual para a mudança de pega, $98 \%$ de acordo com os entrevistados. É preciso que a mesma possua mais pegas, pois de acordo com Iida (2005) a falta destas no fundo de uma embalagem dificulta expressivamente o ato de levantá-la e verte-la.

Mesmo para os modelos Mauser e Coex que já possuem pegas na base inferior de suas embalagens (Figura 2B e C), 64\% e 26\% dos usuários, respectivamente, consideraram necessário à inclusão de mais pegas, pois as existentes são insuficientes.

Uma característica positiva encontrada na Coex é a maior profundidade que a sua pega inferior possui e sua localização no canto oposto ao orifício de saída do produto (Figura 2C), assegurando uma melhor pega ao usuário, mas que juntamente com a alça, obriga o mesmo a manuseá-la sempre da mesma maneira, o que pode causar fadiga muscular pela repetição de movimento.

De acordo com a dificuldade ao abrir a tampa é necessário esclarecer que todas as embalagens analisadas possuem o mesmo modelo de tampa, o Screw Cap. Foi constatado que $74 \%$ dos entrevistados tiveram alguma dificuldade em retirar a tampa (Tabela 2). Esta tampa possui manejo geométrico, o que permite maiores variações de pega já que abrange dimensões antropométricas variadas dos usuários, porém ocasiona alguns pontos de tensão na mão, transmitindo menos força e exigindo maior esforço para executar a ação (IIDA, 1998). De acordo com Kinoshita et al. (1996) as polpas das falanges distal e média localizadas nas pontas dos dedos são utilizadas para pegas circulares, o que confere maior força ao usuário, pois é sabido que quanto maior a área de contato entre a mão e o objeto, maior será o atrito entre eles. 
Tabela 2. Síntese dos aspectos negativos em relação às 03 embalagens.

\begin{tabular}{llc}
\hline & & Porcentagem de Usuários \\
\hline Dificuldade para abrir a tampa da embalagem & SIM & $74 \%$ \\
\hline \multirow{2}{*}{ Ineficácia do sistema para o rompimento do lacre interno } & NÃO & $26 \%$ \\
\hline Força para o rompimento do lacre interno & NÃO & $8 \%$ \\
& MUITA FORÇA & $92 \%$ \\
\hline $\begin{array}{l}\text { Utilizar equipamento de Proteção Individual (EPI) ao manusear } \\
\text { as embalagens }\end{array}$ & SIM & $94 \%$ \\
\hline $\begin{array}{l}\text { Embalagem já causou ferimento nas mãos ao manuseá-la. } \\
\text { NãO }\end{array}$ & SIM & $6 \%$ \\
\hline $\begin{array}{l}\text { Insatisfação quanto à não visualização do agrotóxico dentro da } \\
\text { embalagem }\end{array}$ & SIM & $42 \%$ \\
\hline
\end{tabular}

A textura é outro fator que aumenta a resistência de contato entre os dedos e a superfície da tampa, facilitando a abertura, porém devem ser considerados o material e o tipo de produto e textura a serem utilizados, pois sem um planejamento prévio estas características, aplicadas de forma incorreta, acarretarão no acúmulo de sujeiras comprometendo a higiene (LEWIS; NARAYAN, 1993; PASCHOARELLI; COURY, 2000).

A dificuldade de abrir a tampa leva muitos usuários a utilizarem ferramentas inadequadas para realizar esta tarefa (Figura 4). Esta prática pode gerar acidentes, além de obrigar o usuário a realizar um desvio incorreto no pulso que deveria ficar neutro, pois o desvio ulnar pode causar até $25 \%$ de perda da força, enquanto o radial $20 \%$ e a flexão, caso mais grave, pode reduzí-la entre 40-50\% (MOGK; KEIR, 2003).

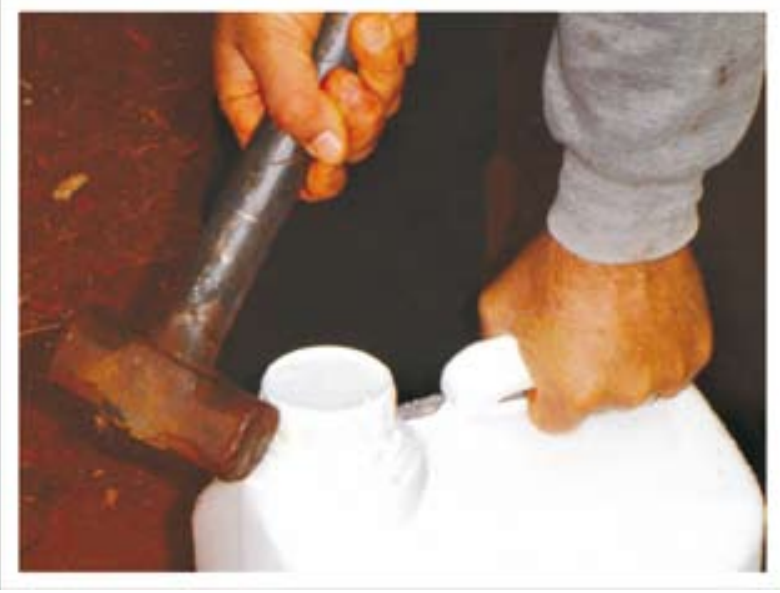

Figura 4. Dificuldade na abertura da tampa

Por fim, deve-se considerar que um produto simétrico funciona tanto para destros quanto para canhotos de acordo com Nicolay e Walker (2005), fundamento este relevante para o design de tampas. 
Também é importante esclarecer que há uma variação considerável quanto à idade dos usuários que fazem uso dessas embalagens, e por isso é preciso ter em mente que o homem entre os 50 e 60 anos pode perder até $25 \%$ de sua força muscular (GRANDJEAN, 1998).

Percebe-se a ineficácia do sistema de rompimento do lacre interno pela alta porcentagem de reprovação
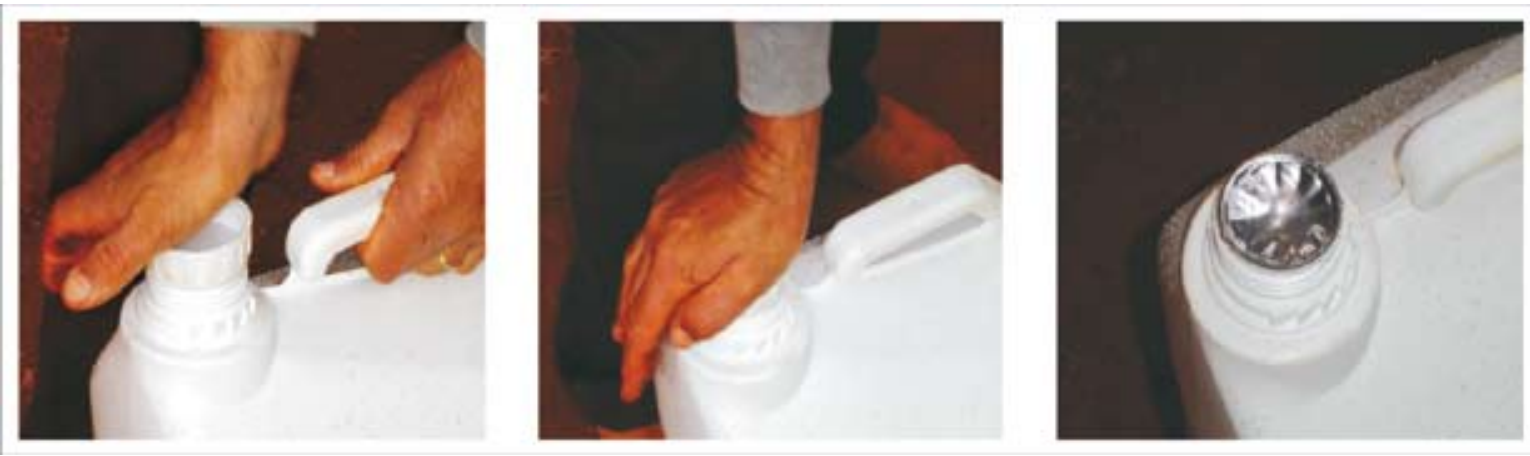

pelos entrevistados (Tabela2), 92\% dos usuários participantes da pesquisa o julgam ineficaz, pois na maioria das vezes o chanfro localizado na parte superior da tampa destinado ao corte do lacre interno não funciona ou então deixa rebarbas que são retiradas com as mãos, aumentando a probabilidade de contato entre o produto e a pele do usuário, o que causa contaminação na falta de equipamentos de proteção individual (Figura 5).

Figura 5. Tentativa de rompimento do lacre

Vale destacar que ocorreram casos em que o usuário utilizou objetos cortantes para auxiliar na remoção do lacre interno, o que também contribui para o aumento da probabilidade de contaminação (Figura 6). A força exigida para o rompimento deste mesmo lacre confirma a ineficácia do sistema da sua abertura (Tabela 2).

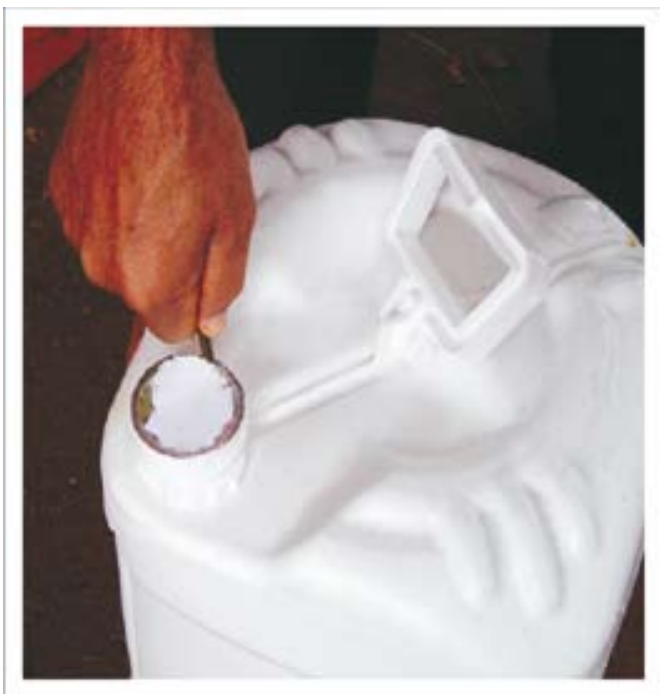

Figura 6. Uso de objeto para remoção do lacre
A força é aplicada na tampa para que o chanfro rompa o lacre. Devido à altura insuficiente do dispositivo de corte, o usuário é obrigado a aplicar uma força excessiva, o que pode causar lesões nas mãos e nos pulsos, pois é fato que no momento descrito a mão não se encontra na posição neutra (Figura 5), o que de acordo com Mogk e Keir (2003) pode ocasionar redução de 40 a $50 \%$ da força. Além da flexão dorsal, o usuário é obrigado a realizar movimentos de desvio ulnar e radial para aumentar o atrito entre a tampa e o lacre.

Devido aos perigos causados pelo contato com o agrotóxico é necessária a utilização de equipamentos de proteção individual (EPI), de acordo com a Tabela 2 mais da metade dos entrevistados (58\%) afirmaram não utilizar nenhum tipo de equipamento de proteção individual. Esse descuido pode acarretar numa série de problemas, já que há grandes possibilidades do usuário se ferir durante o manejo da embalagem, principalmente durante sua abertura, informação que pode ser confirmada com 
a afirmação de $32 \%$ dos entrevistados que alegaram já ter ferido suas mãos no momento do manuseio da embalagem. O contato do agrotóxico com a pele, já causa danos cumulativos e o contato do produto com um ferimento pode potencializar qualquer efeito nocivo do mesmo.

Foi perguntado aos entrevistados se seria interessante poder visualizar o nível de agrotóxico dentro da embalagem, $94 \%$ concordam que a presença de algum dispositivo que permita a visualização do nível do produto dentro da embalagem facilitaria muito o trabalho. Os agricultores entrevistados normalmente utilizam porções menores de agrotóxico, para isso transferem o produto para um segundo recipiente que serve como medidor, para depois colocá-lo no pulverizador. Este processo aumenta o risco de contato do produto com o usuário e, além disso, aumenta a possibilidade de desperdício.

Em relação à preferência das embalagens, a menos votada foi a Mauser (Tabela 3). A Tabela 1 já havia indicado sérios problemas no que diz respeito ao desconforto durante a pega. A alça desta embalagem está localizada numa cavidade, pois foi projetada levando em consideração a possibilidade de empilhamento, característica que impede o movimento efetivo dos dedos e da mão, dificultando seu manuseio. O fato da boca estar no mesmo nível da altura total da embalagem possibilita um maior desperdício de produto e dificulta a tríplice lavagem. Uma característica positiva é o fato de possuir reentrâncias na sua parte inferior, aumentando a superfície de contato com as mãos o que, consequentemente, facilita o ato de vertê-la.

Tabela 3. Distribuição segundo o tipo de embalagem preferida.

\begin{tabular}{ll}
\hline & Fr. relativa \\
\hline Coex & $48 \%$ \\
Mauser & $8 \%$ \\
Retangular & $44 \%$ \\
\hline
\end{tabular}

A segunda embalagem mais votada foi a Retangular, com 44\% de preferência (pouca diferença em relação à primeira colocada - apenas 4\%). Esta embalagem, diferente da Mauser, possui bico afunilado o que facilita o escoamento do produto, sua alça obedece as medidas requeridas pelos estudos antropométricos e não possui muitas reentrâncias que proporcionam o desperdício. A única característica negativa constatada é a falta de apoio no fundo da embalagem, o que dificulta o trabalho do usuário no momento de tombá-la.

A maior preferência dos entrevistados foi pela embalagem Coex. Seu grande diferencial é o sistema de pega, o qual é constituído por uma alça móvel podendo adaptar-se melhor à posição que o usuário desejar. Também possui apoio na superfície inferior, o que possibilita maior segurança no momento de vertê-la. Os pontos negativos envolvem o fato de conter muitas reentrâncias e não possuir afunilamento na boca.

\section{Conclusões}

Por meio das análises realizadas neste trabalho concluiu-se que as embalagens plásticas de 20 litros para agrotóxicos apresentam muitas deficiências e características não favoráveis ao manuseio, como sistema de abertura ineficaz, falta de pegas, alças desconfortáveis e ausência do visualizador do nível do produto. Estes fatores dificultam e prejudicam o desempenho do agricultor, além de aumentar os riscos de lesões.

Devido ao fato das indústrias disporem de pouco tempo para a pesquisa de informações que possibilitem a produção de embalagens ergonomicamente corretas, o guia de parâmetros ergonômicos trará de forma objetiva e relevante os dados teóricos e práticos levantados na pesquisa, possibilitando, desta forma, que estas empresas possam fazer as adequações das bombonas existentes às indicações ergonômicas, proporcionando a 
produção de novos modelos mais confortáveis e amigáveis aos usuários.

OGuia de Parâmetros Ergonômicos, direcionados às indústrias fabricantes de Embalagens Plásticas para Agrotóxicos, trará informações como: espessura ideal de alça, altura adequada do corpo da embalagem, medida mínima para o comprimento do vão da pega, melhor posicionamento para as mesmas e dificuldades apontadas pelos usuários durante o uso das embalagens; tudo isto de forma simples, direta e ilustrada, facilitando a consulta e a compreensão dos designers de embalagens, propiciando, consequentemente, maior segurança e conforto aos agricultores.

\section{Referências}

CONTRERAS, L. R. Aplicación y perspectivas de la ergonomia. In: SIMPOSIUM INTER-NACIONAL DE INGENIERIA INDUSTRIAL, 1, 1996, Aguascalientes. Curso... Aguas-calientes, 1996. 420p.

DESENVOLVIMENTO sustentável: Brasil eleva seu índice de reciclagem de plásticos, figurando entre os países com maiores taxas. Embanews, São Paulo, v. 16, n. 182, p. 46, set. 2005.

DUL, J.; WEERDMEESTER, B. Ergonomia prática. São Paulo: Blücher, 1995.

GOMES, F. J. Ergonomia aplicada ao design industrial dos produtos de uso: reflexão conceitual. 1995. Tese. (Doutorado em Desenho Industrial) - Faculdade de Arquitetura e Urbanismo da Universidade de São Paulo, São Paulo.

GRANDJEAN, E. Manual de ergonomia: adaptando o trabalho ao homem. 4.ed. Porto Alegre: Bookman, 1998.

INSTITUTO NACIONAL DE PROCESSAMENTO DE EMBALAGENS VAZIAS - INPEV. Embalagem de agrotóxicos. 2005a. Disponível em: <http://www.inpev. org.br/institucional/imprensa/clipping/br/noticiaView.as p? noticiaId $=74334343423334234332433424334334343$ 347D251535672604D2132D2634D6611D66435965BB 8>. Acesso em: $15 \mathrm{dez} .2005$.
Identificação das embalagens. Disponível em: <http://www.inpev.org.br/destino_embalagens/ reciclagem_incineracao/identificacao/identificacao_ embalagens.asp >. Acesso em: 15 dez. 2005 b.

IIDA, I. Ergonomia: projeto e produção. São Paulo: Blücher, 1998.

Ergonomia: projeto e produção. 2.ed. São Paulo: Blücher, 2005.

KINOSHITA, H.; MURASE, T.; BANDOU, T. Grip posture and forces during holding cylindrical objects with circular grips. Ergonomics, Toronto, n. 39, p. 11631176, 1996.

LEWIS, W. G.; NARAYAN, C. V. Design and sizing of ergonomic handles for hand tools. Applied Ergonomics, Guildford, Inglaterra, n. 24, p. 351-56, 1993.

MANO, E. B.; MENDES, L. C. Identificação de plásticos, borrachas e fibras. Rio de Janeiro: E.Blücher, 2000. 224 p.

MOGK, J. P. M.; KEIR, P. J. The effects of posture on forearm muscle loading during gripping. Ergonomics, Toronto, v. 46, n. 9, 2003. Disponível em: <www.tandf. co.uk/journals $>$. Acesso em: 10 fev. 2005.

MORAES, A.; MONT'ALVÃO, C. Ergonomia: conceitos e aplicações. 2.ed. Rio de Janeiro: 2AB, 2000.

NICOLAY, C. W.; WALKER, A. L. Grip strength and endurance: influences of anthropometric variation, hand dominance, and gender. International Journal of Industrial Ergonomics, Asheville, v. 35, n. 7, p. 605-618, abr. 2005. Disponível em: <http://www.elsevier.com/ locate/ergon>. Acesso em: 13 jun. 2005.

PASCHOARELLI,L.; COURY,H. Aspectos ergonômicos e de usabilidade no design de pegas e empunhaduras. Estudos em Design, Rio de Janeiro, v. 8, n. 1, p. 79-101, 2000.

PANERO, J.; ZELNIK, M. Las dimensiones humanas en los espacios interiores: estándares antropométricos. 3. ed. México: G. Gilli, 1987. 318 p.

PHEASANT, S. Bodyspace: anthropometry, ergonomics and the design of work. London: Taylor \& Francis, 1988.

RIO, R. P.; PIRES, L. Ergonomia: fundamentos da prática ergonômica. 3.ed. São Paulo: LTr, 2001. 
